\title{
A Screening Test for Iron Deficiency Anaemia and Thalassaemia Traits
}

\author{
AL KABIR ${ }^{\mathrm{a}}$, TF DIPTA ${ }^{\mathrm{b}}$, H KHATUN $^{\mathrm{c}}$, MH RAHMAN ${ }^{\mathrm{d}}$, M HAQ $^{\mathrm{e}}$, MK UDDIN $^{\mathrm{f}}$, M BEGUM $^{\mathrm{g}}$
}

\begin{abstract}
Summary:
Both iron deficiency and thalassaemia trait can present with hypochromic microcytic morphology. Naked eye single tube red cell osmotic fragility (NESTROF) is an inexpensive and simple test which can effectively differentiate iron deficiency anaemia from thalassaemia trait. Our study was an opportunity to observe the role of NESTROF in screening of thalassaemia trait among our study population. Initially NESTROF was carried out in 677 patients $(N)$ population of four groups having both positive and negative NESTORF; for economical issue, auto-analyzer study and
\end{abstract}

\section{Introduction:}

Both Iron Deficiency Anaemia (IDA) and betathalassaemia trait (BTT) are the most frequent causes of microcytic hypochromic anaemia. Iron deficiency anaemia (IDA) may result from insufficient iron intake or menstrual loss, in woman of childbearing age or chronic blood loss in the gastrointestinal tract, in case of elderly subjects. Microcytic anaemia in case of thalassaemia results from impaired globin chain synthesis and decreased haemoglobinization. ${ }^{1}$ Haemoglobinopathies are the common genetic disorders worldwide with estimated $1.5 \%$ of the world population being beta thalassaemia carriers. About 60,000 new

a. Dr. Amin Lutful Kabir, Assistant Professor, Dept. of Hematology, BSMMU, Dhaka.

b. Dr. Tashmim Farhana Dipta, Associate Professor, Haematology and Dept. of Transfusion Medicine, BIRDEM and Ibrahim Medical College, Dhaka.

c. Dr. Hajera Khatun, Specialist, Square Hospital LTD.

d. Dr. Mohammad Hafizur Rahman, Head, Haematology unit, ICDDR,B, Dhaka.

e. Dr. Mahfuz Haq, Haematologist, Dept. of Haematology, AFIP and $\mathrm{CMH}$, Dhaka.

f. Dr. Mohammad Kazim Uddin, Professor, Dept. of Pathology, Northern International Medical College, Dhaka.

g. Prof. Masuda Begum, Professor, Dept. of Hematology, BSMMU, Dhaka

Address of Correspondence: Dr. Amin Lutful Kabir, Assistant Professor, Room No 1510, Block D, Dept. of Haematology, Shahbagh, BSMMU, Dhaka, E-mail: aminlutful@gmail.com Mobile: 01912928326

Received: 21 September, 2013

Accepted: 30 May, 2014 haemoglobin electrophoresis were done among only 100 randomly selected subjects, who were finally included in our study as final study population (n). In our study, NESTROF was $\mathbf{9 4 . 2 3 \%}$ sensitive and its specificity was $\mathbf{9 2 . 0 8 \%}$. The predictive value of a positive test was $88.13 \%$ and predictive value of a negative test was $96.24 \%$. Our study showed, NESTROF can effectively differentiate iron deficiency anaemia (IDA) from thalassaemia trait but, is not effective in co-existent IDA and thalassaemia.

Key Words: NESTROF, IDA, Thalassaemia

(J Banagladesh Coll Phys Surg 2014; 32: 190-193)

carriers are born each year. Fifty percent of world thalassaemia minor are in Southeast Asia including Bangladesh. ${ }^{2}$ a World Health Organization (WHO) report estimates that about $3.0 \%$ of populations are carriers of Beta thalassaemia and $4.0 \%$ are carriers of Hb-E in Bangladesh. World Health Organization (WHO) has recently highlighted the growing concern about anaemia, affecting an estimated 2000 million people, $50 \%$ of the cases caused by iron deficiency (WHO, 2004). ${ }^{3,4}$ Iron deficiency is the most common single nutrient disorder in humans in both developing and developed countries. Iron-deficient erythropoiesis is characterized by the production of RBC with a decreased $\mathrm{Hb}$ concentration and high hypochromic cells percentage, while microcytes of beta thalassaemia are generally smaller, with low Hb content but more preserved $\mathrm{Hb}$ concentration. Hypochromia is the predominant peripheral blood feature in iron deficiency while in thalassaemia the degree of microcytosis relative to hypochromia is more striking. ${ }^{5}$ NESTROFT (naked eye single tube red cell osmotic fragility test) has been used for population surveys, useful in screening for betathalassaemia and the common haemoglobinopathies as a reliable test. It is easy to perform, simple, inexpensive and does not require sophisticated equipment. It has a sensitivity ranging from 94 to 99 per cent. ${ }^{6-8}$ The reliability, low operational cost and rapidity make the test suitable for population screening in the resource poor yet high disease prevalent setting. ${ }^{6-9}$ Our study was an opportunity to observe the role of NESTROF in screening of thalassaemia trait among our study population. 


\section{Materials and Methods:}

This study was done in the Department of Haematology, BSMMU and in the Department of Pathology, Institute of Child Health and Shishu Hospital, Sher-E- Bangla Nagar, Dhaka from $1^{\text {st }}$ January 2003 to $31^{\text {st }}$ December, 2005. The study subject included randomly selected 677 patients $(\mathrm{N})$, both male and female, aged from 12 to 60 years, who took haematology services at the above mentioned institutes. They were then divided into four different groups on the basis of results of complete blood count (CBC) by auto-analyzer, peripheral blood examination in order to identify the normal subjects from those with anaemia. Then serum ferritin (test based on ELISA) and agarose gel haemoglobin electrophoresis tests were done to determine the cause of anaemia among the patients having microcytic hypochromic anaemia. The normal subjects were labeled group -I : 392 subjects with normal haemoglobin, iron status and red cells indices and the rest of the patients were divided into three groups. Group - II: This group comprised of 200 patients who were obligate carrier of either betathalassaemia trait or hemoglobin E trait. Group - III: 60 cases of iron deficiency anaemia (IDA) and thalassaemia trait. Group - IV: 25 patients with iron deficiency anaemia (serum ferritin $<12.0 \mathrm{ng} / \mathrm{ml}$ ) alone. Finally, a total of 100 randomly selected subjects (n) were included in this study from the previous four groups along with positive and negative NESTROF.

Procedure of NESTROF: NESTROF was carried out in all 677 patients with the following procedure: $2.0 \mathrm{ml}$ $0.36 \%$ buffered saline solution ( $\mathrm{pH}-7.4$ ) was taken in one tube and $2.0 \mathrm{ml}$-distilled water was taken in another tube. A drop of venous blood is added in both the tubes and they were left undisturbed for half an hour at room temperature. After half an hour both the tubes were shaken and then held against a white paper on which a thick black line was drawn. This line was also clearly visible through the contents containing distilled water. When the line was similarly visible through the contents of the tube filled with the buffered saline, then the test was considered negative; on the other hand, if the line not clearly visible, the test was considered positive. Moreover, any doubtful conditions were also considered positive.

For calculation, the number of true positive (TP), true negative (TN), false positive (FP) and false negative (FN) were determined. The sensitivity, specificity and predictive values were calculated as follows:
Sensitivity $=($ TP X 100 $) /(T P+F N)$; Specificity $=(T N$ $\mathrm{X} 100)$ / (TN+ FP),

Predictive value of a positive test $=(\mathrm{TP} X 100) /$ (TP+FP) and

Predictive value of a negative test $=(\mathrm{TN} X 100) /$ $(\mathrm{TN}+\mathrm{FN})^{6,7}$

Initially NESTROF was carried out in all 677 patients as $\mathrm{N}$ population, from this population four groups were separated having both positive and negative NESTROF results. However, for economical issue, auto-analyzer study and haemoglobin electrophoresis were done among only 100 randomly selected subjects, who were finally included in this study as final study population (n).

\section{Results:}

Among initial 677 patients (N), NESTROF was positive in 278 cases, of these 245 cases

(group-II and III) are obligate carriers of both Beta thalassaemia trait and Haemoglobin-E trait and they were true positive (TP) and 28 (group-I) did not have any abnormal haemoglobin and they were false positive (FP) (table I). 33 cases (normal subject- group I and IDA-group IV) were false positive (FP). The test was negative in 399 individuals, with 384 true negatives (TN) and 15 false negatives were (FN) (thalassaemia trait-group II and IDA and thalassaemia trait- group III).Finally, due to cost issue for auto-analyzer study and haemoglobin electrophoresis, a total of 100 randomly selected subjects were included in our study as final study population (n), from the previous four groups along with positive and negative NESTROF. Sensitivity and specificity of NESTROF was shown to be $94.23 \%$ and $92.08 \%$ respectively. Calculation also showed predictive value of a positive test was $88.13 \%$ and predictive value of a negative test was $96.24 \%$.The result of NESTROF was evaluated with $\mathrm{Hb} \%$, Red Cell Indices (Red Cell Count, MCV, and MCH) (Table II). This result showed that low MCV \& MCH with a relatively high Red Cell Count (as found in thalassaemia traits) was associated with positive NESTROF and low MCV, MCH associated with low Red cell Count (as found in iron deficiency anaemia) was associated with negative NESTROF. Results of estimation of $\mathrm{HbA}_{2}$ and Haemoglobin-E in agarose gel electrophoresis among the 100 study subjects (n) (Table III) shows that in co-existent IDA and thalassaemia trait, there was a drop in $\mathrm{Hb}$ A2. 
Table-I

\begin{tabular}{lcccc}
\multicolumn{4}{c}{ Results of NESTROF $(N=677)$ in four groups } & \\
Groups & Final Study & NESTROF & NESTROF & NESTROF \\
& subjects $(\mathrm{n}=100)$ & Positive & negative & (N= 677) \\
\hline Group-I(Normal subjects) & 38 & $28(7.14 \%)$ & $364(92.86 \%)$ & 392 \\
Group-II(Beta thalassaemia traits or Hb E trait) & 12 & $189(94.50 \%)$ & $11(5.50 \%)$ & 200 \\
Group-III(both IDA \& thalassaemia trait) & 25 & $56(94.50 \%)$ & $04(5.50 \%)$ & 60 \\
Group-IV(IDA) & 25 & $05(20 \%)$ & $20(80 \%)$ & 25 \\
Total number of cases & 100 & $278(41.06 \%)$ & $399(58.94 \%)$ & 677 \\
\hline
\end{tabular}

\section{Table-II}

\begin{tabular}{|c|c|c|c|c|c|c|}
\hline \multicolumn{7}{|c|}{ NESTROF $(N=677)$ along with auto- analyzer haematological values of final study subjects $(n=100)$} \\
\hline $\begin{array}{l}\text { Final Study } \\
\text { subjects }(n=100)\end{array}$ & $\begin{array}{c}\mathrm{Hb}(\mathrm{g} / \mathrm{L}) \\
\text { (Mean) }\end{array}$ & $\begin{array}{c}\text { Red Cell } \\
\text { Count (mean) }\end{array}$ & $\begin{array}{c}\text { MCV } \\
\text { (Mean) }\end{array}$ & $\begin{array}{c}\text { MCH } \\
\text { (Mean) }\end{array}$ & $\begin{array}{c}\text { NESTROF } \\
(+) \mathrm{VE}\end{array}$ & $\begin{array}{c}\text { ESTROF } \\
(-) \mathrm{VE}\end{array}$ \\
\hline Normal (38) & 12.0 & $4.8 \times 10^{12} / / \mathrm{L}$ & $82 \mathrm{fl}$ & $30.4 \mathrm{pg}$ & 28 & 364 \\
\hline Beta trait(12) & 10.5 & $4.9 \times 10^{12} / / \mathrm{L}$ & $73 \mathrm{fl}$ & $23 \mathrm{pg}$ & 189 & 11 \\
\hline Hb-E trait(25) & 11.2 & $5.10 \times 10^{12} / / \mathrm{L}$ & $78 \mathrm{fl}$ & $24 \mathrm{pg}$ & 56 & 04 \\
\hline IDA(25) & 7.8 & $3.6 X 10^{12} / / \mathrm{L}$ & $65 \mathrm{fl}$ & $68 \mathrm{pg}$ & 05 & 20 \\
\hline
\end{tabular}

Table-III

Pattern of Hb Electrophoresis in the study subjects $(n=100)$

\begin{tabular}{lcccc} 
Interpretations & \multicolumn{3}{c}{ Haemoglobin pattern } \\
& $\mathrm{Hb} \mathrm{A}$ & $\mathrm{HbA}_{2}$ & $\mathrm{Hb} \mathrm{F}$ & $\mathrm{HbE}+\mathrm{HbA}$ \\
\hline Normal & $96.60 \%$ & $2.20 \%$ & $1.20 \%$ & - \\
Beta-Thalassemia trait & $94.10 \%$ & $4.10 \%$ & $1.80 \%$ & - \\
E trait & $71.50 \%$ & - & $1.20 \%$ & $27.30 \%$ \\
Both IDA \& thalassemia trait & $96.60 \%$ & $1.80 \%$ & $1.60 \%$ & - \\
\hline
\end{tabular}

N.B: In Agarose Gel Haemoglobin Electrophoresis, $\mathrm{HbE} \& \mathrm{HbA}_{2}$ appear in the same position and could not be isolated as a separate band. It is possible only if electrophoresis is performed on acid media.

\section{Discussion:}

In our study, sensitivity and specificity of NESTROF was shown to be $94.23 \%$ and $92.08 \%$ respectively; which was similar to that of Mehta et. al. and Kattamis et. al, where specificity $92.08 \%$ and sensitivity $94.23 \%{ }^{6}$ We found the test effective in detecting almost $100 \%$ of subjects with Beta-thalassaemia trait, while it gives false positive results in nearly $10 \%$ of normal subjects. ${ }^{6,}{ }^{7}$ It is important to note that in beta-thalassaemia trait the concentration of haemoglobin A2 which is usually elevated, may be significantly reduced due to the coexistent IDA making the diagnosis extremely difficult which can be missed even in Hb-electrophoresis. This is of particular importance when a study is conducted in an area where iron deficiency is also prevalent like our country. Importance of the study of Peripheral Blood (PB) with red cell indices, serum ferritin and $\mathrm{Hb}$ electrophoresis are paramount for proper diagnosis of 
coexisting iron deficiency anaemia (IDA) and thalassaemia trait (beta thalassaemia trait or haemoglobin-E trait). ${ }^{12}$ For the diagnosis of iron deficiency anaemia clinical findings, presence of hypochromic microcytic blood picture and low serum ferritin levels $(<10 \mathrm{ng} / \mathrm{ml})$ are needed. Some patients may presents with chronic anaemia, sore tongues, angular stomatitis, cheliosis or koilonychias. So in our study the limitation was, to differentiate co-existent trait and IDA, as in coexisting IDA with thalassaemia trait the NESTROF test may not be effective, found in other Bangladeshi study. ${ }^{13}$ In our study, the results of NESTROF were evaluated with $\mathrm{Hb} \%$, Red Cell Indices. Low MCV \& MCH with a relatively high Red Cell Count found in thalassaemia traits was associated with positive NESTROF while low MCV, MCH with low Red Cell Count found in iron deficiency anaemia was associated with negative NESTROF in our study. Thus our study showed, NESTROF can effectively differentiate between thalassaemia trait and iron deficiency. This study also showed, NESTROF was easy to perform, less technical expertise and no initial capital outlay were required as like as other studies. ${ }^{6-9,13,14}$

\section{Conclusion:}

Our study showed NESTROF as a valuable screening tool differentiate thalassaemia trait and IDA. On the other hand, as in coexisting IDA with thalassaemia trait the NESTROF test may not be effective, so further study will be needed to see the response of oral iron therapy to identify true iron deficient patients. In areas with limited laboratory facilities and for field screening NESTROF can be used in diagnosing and counseling thalassaemia carriers, thus may help to prevent thalassaemia in our country.

\section{Acknowledgement:}

We express our gratitude to all of our patients and their parents.

\section{Conflict of Interest: None}

\section{References:}

1. Urrechaga E. Red blood cell microcytosis and hypochromia in the differential diagnosis of iron deficiency and bthalassaemia trait Int. Jnl. Lab. Hem. 2009; 31: 528-534.
2. Niazi M, Tahir M, Raziq F, Hameed A. Usefulness of red cell indices in differentiating microcytic hypochromic anemias. Gomal Journal of Medical Sciences July-December 2010; 8 (2): 125-129.

3. Rahman MJ, Rahman MH, Prevention \& control strategy of thalassemia in Bangladesh. The Orion Vol. 16 Sep. 2003; 121-122.

4. Khan WA. Thalassemia in Bangladesh. DS (Children) H Journal 1999; June -December, 15 (1, 2): 42-44.

5. Urrechaga E, Borque L, Escanero JF. The role of automated measurement of red cell subpopulations on the Sysmex XE 5000 analyzer in the differential diagnosis of microcytic anemia. Int. Jnl. Lab. Hem. 2011; 33: 30-36.

6. Mehta BC, Gandhi S, Mehta JB, Kamath P. Naked eye single tube red cell osmotic fragility test for b-thalassemia: Population survey. Indian J Hemat 1988; 6:187-190.

7. Gomber S, Sanjeev, Madan N. Validity of NESTROF in screening and diagnosis of beta-thalassemia trait. Department of Pediatrics, University College of Medical Sciences. J Tro Pedir, 1997 Dec, 43:6, 363-6.

8. Basu S, Kumar A, Sachdeva MP, Saraswathy KN. Incidence of NESTROF-Positives and Haemoglobin S among the Jats and Brahmins of Sampla, Haryana. Anthropologist 2008; 10(3): 203-205.

9. Mamtani M, Jawahirani A, Kishor D, Rughwani V,Hemant $\mathrm{K}$. Bias-corrected diagnostic performance of the naked eye single tube red cell osmotic fragility test (NESTROFT): An effective screening tool for â-thalassaemia. Hematology 2006; 11 (4) : $277-286$.

10. Lokeshwar MR. Present knowledge in the management of thalassemia and abnormal hemoglobinopathies. Pedir Clin India 1989; 24: 10-18.

11. Frank F, Colin C, David P, Bryan R. Hypochromic anaemia. De Gruchy's Clinical Haematology in Medical Practices, 6th edition, 2002.

12. Aearly HV, Altman DG, Pippard MJ. Microcytosis, iron deficiency, and thalassemia in preschool children. Archives of Disease in Childhood, 1990; 65:610- 614.

13. Begum JA, Amin SK, Khan WA, Banu B, Selimuzzaman M, Sharmin S, Hossain B. Evaluation of naked eye single tube red cell osmotic fragility test (NESTROF) in detecting betathalassaemia trait. DS (Child) H J 2005; 21 (2); 44- 48.

14. Mamtani M, Das K, Jawahirani A, Rughwani V, Kulkarni H. Is NESTROF sufficient for mass screening for â- thalassaemia trait? J Med Screen 2007; 14: 169-173. 